\title{
Increased Numbers of Circulating Th22 and Th17 Cells in Patients with Kawasaki Disease
}

\author{
Liwen Zhang, Liang Ma et al ${ }^{1}$ \\ ${ }^{1}$ Affiliation not available
}

September 13, 2021

\section{Introduction}

Kawasaki disease (KD), also known as Kawasaki syndrome, is an acute, self-limited febrile vasculitis that predominantly affects infants and children under 5 years of age [1]. KD is characterized by high spiking fever persisting for more than 5 days, erythematous rash, bilateral conjunctivitis, congestive oral mucosa, swelling lymph node, and edematous extremity [2]. Furthermore, KD is the most common cause of acquired cardiac disease, especially coronary artery aneurysms in children [3]. Although KD has been studied for almost half a century, the pathogenic mechanism of KD remains unclear. Furthermore, while most patients respond well to intravenous immunoglobulin (IVIG), roughly one-quarter of the children meeting clinical criteria will go on to have coronary artery inflammation, including aneurysms [4]. Hence, further illustration of the mechanism of KD is a crying need to find a therapeutic for KD treatment clinically.

Both innate and adaptive immune systems are involved in the pathogenesis of KD [5]. The early event of visualized immunological abnormality is the activation of innate immune system represented as the elevated numbers of activated monocytes and increased expression of circulating cytokines, such as interleukin (IL)-6 and tumor necrosis factor (TNF) $-\alpha[6]$. Subsequently, it is generally believed that autoreactive $\mathrm{T}$ cell and their inflammatory cytokines play a major role in the development of KD [7]. T helper (Th) 17 cells, a recently identified lineage of CD4+ Th cells, predominantly produce IL-17A. Th17 cell and IL-17A have been shown to participate in host defense responses and inflammatory diseases, such as systemic lupus erythematosus (SLE), rheumatoid arthritis (RA), Graves' disease (GD), and Crohn's disease (CD) [8-11]. A recent study has shown that a high frequency of Th17 cells and high levels of IL-17 were demonstrated in the acute stage of $\mathrm{KD}$, and that elevated Th17 cells might be associated with tissue damage and coronary artery aneurysm formation [7, 12]. However, there is little information about whether higher frequency of Th17 and higher concentrations of IL-17A also exist in Chinese patients with KD and how Th17 responses are associated with the development of coronary artery aneurysm in KD patients.

More notably, a newly identified T-cell subset, termed Th22 cells, has been described as expressing their key cytokines interleukin (IL)-22, which can activate signal transduction and transcription 3 (STAT3) [13]. IL-22, originally termed as an IL-10-related T-cell-derived-inducible factor, enhance innate immunity and promote epithelial cell proliferation and tissue. In contrast, IL-22 also act as regulator in the pathogenesis of RA and SLE [14-15]. Furthermore, recent studies have reported that IL-22 may function as a biphasic cytokine: protective and regenerative in steady state while amplifying proinflammatory signals given by TNF- $\alpha[16]$, which is necessary for exacerbation of vascular injury in KD. However, little is known about the role of Th22 cells in the pathogenesis of KD. We believe that Th22 cells may partially contribute to the formation of coronary aneurysms.

Here, in the current study, we sought to further clarify the mechanism underlying hyperactivation of Th22 and Th17 during acute KD. We characterized the numbers of circulating Th22 and Th17 cells by flow cytometry, and measured the concentration of serum inflammatory cytokines by enzymelinked immunosorbent assay 
(ELISA) in 43 Chinese patients with new onset KD. Furthermore, we analyzed the potential association of the numbers of Th22 and Th17 cells with the clinical measures in these KD patients. Our findings indicated that increased numbers of Th22 and Th17 cells might be contributed to the pathogenesis of KD in Chinese patients.

\section{Materials and Methods}

\section{subjects}

A total of 43 patients with newly onset KD were recruited sequentially at the inpatient clinic of Department of Pediatrics, the Second People's Hospital of Changzhou, Affiliate Hospital of NanJing medical University, China. Another 20 age-, gender-and ethnicity-matched healthy controls (HCs) were recruited during the same period, and they had no a history of any chronic inflammatory disease. Individual patients with KD were diagnosed, according to the international criteria of the 2004 American Heart Association (AHA) statement [1]. The severity of coronary artery dilation in those patients were assessed using the Z-score (normalized luminal dimensions for body surface area), and a Z-score $>2$ was defined as a coronary artery abnormality $(\mathrm{CAL}+)$ [17]. 17 of among the KD patients were diagnosed with coronary artery lesions by echocardiography. Patients with any of other autoimmune diseases, recent infection or those who had received immune suppressive therapies or glucocorticoid therapies were excluded from the study. All patients underwent the same treatment options, which were the administration of IVIG at a dose of $2 \mathrm{~g} / \mathrm{kg}$ for 1 day and oral aspirin at a dose of 30-50 mg/kg per day from the establishment of diagnosis to defervescence. After IVIG administration, all patients were in remission, at which stage the patients had been afebrile for at least $48 \mathrm{~h}$. All subjects signed an informed consent form prior to the initiation of the study, and the study was approved by the Ethical Committee of the Second People's Hospital of Changzhou.

\section{Clinical examination}

The clinical data of each subject was collected from the hospital records. These data included age, sex, and laboratory tests. Individual subjects were subjected to routine laboratory tests for full blood cell counts, C-reactive protein (CRP), erythrocyte sedimentationrate (ESR), N-terminal pronatriuretic peptide (NTproBNP), and the concentrations of serum immunoglobulins (Ig)G, M, A and complement (C)3, 4 by a biochemistry automatic analyzer (Roche Diagnostics, Branchburg, USA) and scatterred turbidimetry on a Siemens special protein analysis instrument (Siemens Healthcare Diagnostics Products, GmbH, Germany).

\section{Flow cytometric analysis of intracellular cytokine staining}

Freshly isolated peripheral blood mononuclear cells (PBMCs) of KD patients were stimulated in duplicate with $50 \mathrm{ng} / \mathrm{mL}$ of phorbol myristate acetate (PMA) and $1.0 \mathrm{mg} / \mathrm{mL}$ of ionomycin (Sigma, St. Louis, MO, USA) in RPMI 1640 medium at room temperature in a humidified incubator with $95 \%$ air and $5 \%$ carbon dioxide for 2 hours and then cultured for another 4 hours in the presence of $0.5 \mathrm{mg} / \mathrm{mL}$ of brefeldin A (BFA, Sigma). The numbers of CD ${ }^{+} \mathrm{CD} 4{ }^{+} \mathrm{IL}-22^{+} \mathrm{Th} 22, \mathrm{CD} 3^{+} \mathrm{CD} 4^{+} \mathrm{IL}-17^{+} \mathrm{Th} 17$ and $\mathrm{CD} 3^{+} \mathrm{CD} 4{ }^{+} \mathrm{IFN}-\gamma^{+} \mathrm{Th} 1$ cells in individual samples were determined by flow cytometry following intracellular staining with anti-cytokine antibodies.

\section{$\mathrm{E} \nu \zeta \psi \mu \varepsilon-\lambda \iota \nu x \varepsilon \delta$ I $\mu \mu \nu \nu \circ \sigma o \rho \beta \varepsilon \nu \tau \alpha \sigma \sigma \alpha \psi \varphi \rho \rho \mathrm{I} \Lambda-6, \mathrm{TN} \Phi-\alpha, \mathrm{I} \Phi \mathrm{N}-\gamma, \mathrm{I} \Lambda-17 \alpha \nu \delta \mathrm{I} \Lambda-22$}

The cytokine levels in the serum were collected and allowed to clot at $4{ }^{\circ} \mathrm{C}$ for 2 hours. The clots were removed by centrifuging at $7000 \mathrm{rpm}$ for $30 \mathrm{~min}$ in a refrigerated centrifuge. Serum was obtained from all subjects by centrifugation and stored at $-80^{\circ} \mathrm{C}$ for determination of cytokines levels. The levels of cytokines in the serum/supernatant were measured by Enzyme-linked Immunosorbent Assay (ELISA) using commercially available IL-6, TNF- $\alpha$, IFN- $\gamma$, IL-17 and IL-22 ELISA kits (BOSTER, Wuhan, China) according to the manufacturer's instructions.

\section{Statistical analysis}

The differences between the groups were analyzed by Mann-Whitney test and Wilcoxon signed rank test using SPSS 18.0 software for unpaired and paired comparisons, respectively. The relationship between 
variables was evaluated using the Spearman rank correlation test. A two-side $\mathrm{P}$ value $<0.05$ was considered statistically significant.

\section{Results}

\section{Patient characteristics.}

The demographic characteristics of KD patients and $\mathrm{HC}$ were summarized in Table 1. As expected, the WBC, lymphocyte and Lymphocytes counts and the levels of serum ESR and CRP in the patients were significantly higher than that in the HC. Furthermore, the concentrations of serum NT-proBNP in KD patients with CAL were significantly higher than that in KD group with NCAL. In contrast, there was no significant difference in the distribution in the gender and age, and the levels of serum $\operatorname{IgG}, \operatorname{IgM}, \operatorname{IgA}, \mathrm{C} 3$ and $\mathrm{C} 4$ among the different groups of patients and HCs.

\section{Increased numbers of Th22 and Th17 cells in KD patients.}

We first characterized the levels of different subset of effector $\mathrm{CD} 3^{+} \mathrm{CD} 4^{+} \mathrm{T}$ cells in $\mathrm{KD}$ patients by flow cytometry analysis. As shown in Fig 1, KD patients with CAL had significantly increased numbers of CD $3^{+} \mathrm{CD} 4{ }^{+} \mathrm{IL}-22^{+} \mathrm{Th} 22$ and $\mathrm{CD} 3{ }^{+} \mathrm{CD} 4^{+} \mathrm{IL}-17^{+}$Th17 cells compared to KD patients with NCAL and HCs $\left[\right.$ Th22 $(1.62 \pm 0.29) \times 10^{4}$ versus $(1.10 \pm 0.27 \%) \times 10^{4}$ versus $(0.85 \pm 0.21 \%) \times 10^{4}, \mathrm{P}<0.05$, Th17 $(2.80 \pm$ $0.78 \%) \times 10^{4}$ versus $(2.07 \pm 0.66 \%) \times 10^{4}$ versus $\left.(2.07 \pm 0.41 \%) \times 10^{4}, \mathrm{P}<0.05\right]$. Furthermore, KD patients with NCAL had significantly increased numbers of $\mathrm{CD} 3^{+} \mathrm{CD} 4^{+} \mathrm{IL}-22^{+} \mathrm{Th} 22$ and $\mathrm{CD} 3^{+} \mathrm{CD} 4{ }^{+} \mathrm{IL}-17^{+} \mathrm{Th} 17$ cells compared to HCs $(\mathrm{P}<0.05)$. However, we did not find a significant difference in the numbers of $\mathrm{CD} 3{ }^{+} \mathrm{CD} 4{ }^{+} \mathrm{IFN}-\gamma^{+}$Th1 cells among the different groups of patients and HCs [ $(24.80 \pm 4.15) \times 10^{4}$ versus $(22.22 \pm 5.12) \times 10^{4}$ versus $\left.(25.33 \pm 4.84) \times 10^{4}, \mathrm{P}>0.05\right]$.

\section{Higher concentrations of serum IL-22 and IL-17 were present in KD patients}

To determine the function of different subsets of IL-22- and IL-17A-producing CD4+ T-cells, we measured the concentrations of serum IL-22, IL-17A and IFN- $\gamma$ in the patients (Fig 2). We found that the concentrations of serum IL-22 and IL-17A in KD patients with CAL were significantly higher than that in KD patients with NCAL and HCs [IL-22 (18.59 \pm 4.15$)$ versus $(13.65 \pm 5.77)$ versus $(8.57 \pm 1.69), \mathrm{P}<0.05$, IL-17 $(78.51$ $\pm 22.37)$ versus $(53.16 \pm 16.35)$ versus $(40.74 \pm 11.68), \mathrm{P}<0.05]$. However, we did not find a significant difference in the concentrations of serum IFN- $\gamma$ among the different groups of patients and HCs [(13.19 \pm $4.23)$ versus $(11.76 \pm 2.77)$ versus $(11.46 \pm 3.96), \mathrm{P}>0.05]$. TNF- $\alpha$ is necessary for exacerbation of vascular injury in KD. We further analyzed the levels of TNF- $\alpha$ in the serum of KD patients and found a higher level of serum TNF- $\alpha$ in KD patients with CAL, compared to KD patients with NCAL and HC [(14.36 \pm $3.85)$ versus $(7.78 \pm 3.21)$ versus $(5.25 \pm 2.01), \mathrm{P}<0.05]$. In addition, the concentrations of serum IL-6 in $\mathrm{KD}$ patients were significantly higher than that in the $\mathrm{HCs}[(8.96 \pm 2.39)$ versus $(8.49 \pm 2.29)$ versus $(3.73$ $\pm 1.24), \mathrm{P}<0.05]$.

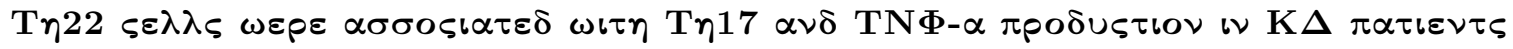

We analyzed the relationship among the numbers of circulating Th22, Th17 and TNF- $\alpha$ in KD patients. We found that the numbers of Th22 cells were significantly positively correlated with the numbers of Th17 cells in KD patients with CAL $(R=0.494, P=0.044$, Fig. 3A). Further analysis revealed that the numbers of circulating Th22 and Th17 cells were correlated positively with the levels of serum IL-22 and IL-17A in KD patients with CAL, respectively $(R=0.647, P=0.005$, Fig. $3 \mathrm{~B} ; R=0.774, P=0.003$, Fig. 3D). In addition, the numbers of circulating Th22 cells were correlated positively with the levels of serum TNF- $\alpha$ in KD patients with CAL $(R=0.756, P<0.001$, Fig. $3 \mathrm{C})$. Moreover, KD patients with NCAL also showed the same trend $(R=0.522, P=0.006$, Fig. $3 \mathrm{E} ; R=0.676, P=0.002$, Fig. $3 \mathrm{~F} ; R=0.643, P<0.001$, Fig. $3 \mathrm{G} ; R$ $=0.491, P=0.011$, Fig. 3H; respectively).

\section{Th22 and Th17 cells were associated with clinical parameters in KD patients}

To determine the pathogenic role of Th22 and Th17 cells in the development of KD, we analyzed the potential association of the levels of these $\mathrm{CD} 3{ }^{+} \mathrm{CD} 4{ }^{+} \mathrm{T}$ cell-related cytokines with the values of clinical parameters 
in KD patients. We found that the concentrations of serum IL-22 and IL-17 were correlated positively with the concentrations of ESR, CRP and NT-proBNP in KD patients with CAL, respectively $(R=0.653, P$ $=0.005 ; R=0.506, P=0.038 ; R=0.609, P=0.009$, Fig. $4 \mathrm{~A} ; R=0.743, P<0.001 ; R=0.837, P<0.001 ; R$ $=0.597, P=0.011$, Fig. $4 \mathrm{~B}$; respectively). Moreover, KD patients with NCAL also showed the same trend $(R=0.753, P<0.001 ; R=0.504, P=0.009 ; R=0.406, P=0.039$, Fig. $4 \mathrm{C} ; R=0.561, P=0.003 ; R=0.444$, $P=0.023 ; R=0.492, P=0.011$, Fig. $4 \mathrm{D}$; respectively).

\section{Altered numbers of Th22/Th17 cells and related cytokines in KD patients after treatment}

Finally, we tested how the treatment with intravenous immunoglobulin (IVIG) affected the numbers of Th22/Th17 cells and the concentrations of serum IL-22, IL-17A and TNF- $\alpha$ in the patients (Fig. 5) We found that the numbers of Th22 and Th17 cells were significantly lower than that before the treatment $\left[\mathrm{Th} 22 \mathrm{CAL}^{+}(1.61 \pm 0.29) \times 10^{4}\right.$ versus $(0.84 \pm 0.21) \times 10^{4}, \mathrm{P}<0.05$, Th17 $\mathrm{CAL}^{+}(2.80 \pm 0.78) \times 10^{4}$ versus $(1.64 \pm 0.45) \times 10^{4}, \mathrm{P}<0.05$, Th22 $\mathrm{CAL}^{-}(1.09 \pm 0.27) \times 10^{4}$ versus $(0.79 \pm 0.17) \times 10^{4}, \mathrm{P}<0.05$, Th17 $\mathrm{CAL}^{-}$ $(2.07 \pm 0.66) \times 10^{4}$ versus $\left.(1.48 \pm 0.34) \times 10^{4}, \mathrm{P}<0.05\right]$. Similarly, the concentrations of serum IL-22 and IL-17A in those patients with CAL and NCAL after the treatment were also significantly lower than that before the treatment $\left[\mathrm{IL}-22 \mathrm{CAL}^{+}(18.59 \pm 4.15)\right.$ versus $(8.78 \pm 1.71), \mathrm{P}<0.05, \mathrm{IL}^{-17} \mathrm{CAL}^{+}(78.51 \pm 21.37)$ versus $(40.35 \pm 11.05), \mathrm{P}<0.05$, IL-22 $\mathrm{CAL}^{-}(13.65 \pm 5.77)$ versus $(8.50 \pm 1.69), \mathrm{P}<0.05, \mathrm{IL}_{-17} \mathrm{CAL}^{-}(53.16$ $\pm 16.35)$ versus $(38.56 \pm 9.80), \mathrm{P}<0.05]$. Morever, the concentrations of serum TNF- $\alpha$ in those patients with CAL and NCAL after the treatment were lower than that before the treatment $\left[\mathrm{CAL}^{+}(14.36 \pm 3.85)\right.$ versus $(5.41 \pm 2.04), \mathrm{P}<0.05, \mathrm{CAL}^{-}(7.78 \pm 3.21)$ versus $\left.(4.94 \pm 1.841), \mathrm{P}<0.05\right]$.

\section{Discussion}

Although dysregulated activation of effector $\mathrm{CD} 3^{+} \mathrm{CD} 4^{+} \mathrm{T}$ helper cell are involved in the pathogenic process of $\mathrm{KD}[7,12]$, this specific mechanism remain unknown. In this study, we found that the numbers of circulating Th17 cells in KD patients, but not Th1 cells, were significantly greater than those in the HC, which were consistent with previous studies [7]. However, our finding were different from another report that displayed an equivalent levels of circulating Th17 cells [18]. Conflicting results may be due to enrollment of patients. Morever, these inconsistencies are partly due to differences in methodology, or detection markers of the definition of Th17 cell. Indeed, the pathogenic mechanism of Th17 cells in the development of KD depends on the phase of their disease. Consistently, the concentrations of serum IL-17A, but not IFN- $\gamma$, in KD patients were significantly higher than that in the $\mathrm{HC}$, consistent with a previous study [7]. More importantly, we found that the numbers of circulating Th17 cells were correlated positively with the concentrations of serum IL-17A in those patients. These suggest that Th17 cells are major producers of IL-17A in KD patients. Based on our data, serum IL-17A were correlated positively with ESR and CRP, indicating that Th17 cell contribute to innate immune responses. More importantly, our data showed also a high expression level of Th17 cells and serum IL-17A in KD patients with CAL compared to the KD patients with NCAL. Additionally, the concentrations of serum IL-17A in KD patients with CAL were correlated positively with the concentrations of NT-proBNP, which are a hallmark of CAL [19], suggesting Th17 cells contribute to the progression of CALs. This possible mechanism is that the proinflammatory cytokine IL-17A acts on a broad range of cells, including neutrophils and monocytes, to induce the expression of additional proinflammatory cytokines such as TNF- $\alpha[20]$. Our novel findings may provide new insights into understanding the pathogenesis of CAL.

In addition to Th17 cells, Th22 cells expressing aryl hydrocarbon receptor (AHR) are associated with numerous autoimmune diseases, such as SLE, RA and ankylosing spondylitis (AS) [14-15, 21]. However, the possible mechanisms of Th22 cells in the development of KD remain unclear. In this study, we found that the numbers of circulating Th22 cells and the concentrations of serum IL-22 in KD patients were significantly greater than those in the HC. These results extend previous observations and support the notion that Th22 cells, like Th17 cells, also have major functions in the pathogenesis of KD. It is possible that the inflammatory environment in the development of KD preferably activates naive helper $\mathrm{T}$ cells towards Th1 and Th17 directions [22]. Morever, we found that the numbers of circulating Th22 cells were correlated positively with the concentrations of serum IL-22 in KD patients, suggesting that IL-22 is predominantly secreted by Th22 cells in those patients. More importantly, serum IL-22 were correlated positively with ESR 
and CRP, indicating that Th22 cells might serve as a biomarker for indicating disease severity or prognosis of KD, which, however, should be confirmed in future studies with a larger sample size. There are limitations in our study. Furthermore, we found a high expression level of Th22 cells and serum IL-22 in KD patients with CAL compared to the KD patients with NCAL and the concentrations of serum IL-22 were correlated positively with the concentrations of NT-proBNP in patients with CAL. These suggest that Th22 cells collaborate and contribute to the pathogenesis of CALs. Notably, our data revealed that the numbers of circulating Th22 cells in KD patients were correlated positively with the concentrations of serum TNF- $\alpha$, which were an independent risk factor associated with a significantly longer median time to recovery of CALs [23]. Therefore, the current data provide a possibility that Th22 cells might induces the secretion of TNF- $\alpha$, which further cause the occurrence of CAL. We are interested in further investigating the specific mechanism of Th22 cells in the process of CAL.

Treating affected patients with IVIG has been demonstrated to control symptoms and inhibit coronary aneurysm formation effectively in KD patients with CAL [24]. The precise mechanism of IVIG in the treatment of KD remains unclear. We found that the treatment with IVIG reduced significantly the numbers of circulating Th22 and Th17 cells and the concentrations of serum IL-22 and IL-17 in KD patients. It is possible that immunosuppressants mainly induce the proliferation of naive $\mathrm{T}$ cells to regulatory $\mathrm{T}$ cells, rather than effector T cells. Morever, the treatment with IVIG also reduced significantly the concentrations of serum TNF- $\alpha$ in KD patients. Consequently, these findings suggest that treatment with IVIG may be more effective in modulating the imbalance between effector and Tregs in KD patients.

In summary, our data showed significantly increased numbers of Th22 and Th17 cells, but not Th1 cells, as well as higher levels of Th22/Th17-type cytokines in KD patients. More importantly, serum IL-17A and IL-22 levels were positively correlated with the ESR, CRP and NT-proBNP. Meanwhile, treatment with IVIG not only effectively improved clinical symptoms, but also reduced the numbers of Th22 and Th17 cells and their cytokines in KD patients. The presented data might provide new insights into understanding the pathogenesis of $\mathrm{KD}$ and aid in developing an effective therapy for use in the patients who have already developed coronary artery lesions. However, we recognized that our study had limitations, such as a relative small sample size and the absence of functional study of Th22 and Th17 cells in the pathogenic process of KD. Therefore, further longitudinal studies of the real function of Th22 and Th17 cells in the pathogenic process of KD with a bigger population are warranted.

\section{Acknowledgements}

This study was supported by grants from the Changzhou Sci\&Tech Program (Grant No.CZQM2020011; CZQM2020079), Natural Science Foundation of Xinjiang Uygur Autonomous Region (2021D01F64), the National Natural Science Foundation of China (No. 81700500), the Applied Basic Research Programs of Science, Technology Department of Changzhou city (CJ20160031; CJ20190095), the Research Project of Jiangsu Province Commission of Health and Family Planning (No. H201547), the Major Scientific and Technological Project of Changzhou City Commission of Health and Family Planning (No. ZD201612) and the Scientific and Technological Project of NanJing medical University (No. 2017NJMU042).

\section{Disclosures}

All authors declared there were no conflict interests invoved.

\section{Data Availability Statement}

Data are available on request from the authors.

\section{References}

1. McCrindle BW, McCrindle BW, Rowley AH, et al. Diagnosis, Treatment, and Long-Term Management of Kawasaki Disease: A Scientific Statement for Health Professionals From the American Heart Association. Circulation 2017; 135: 927-999. 
2. Vincent P, Quentin H, Jean-Michel G, Denis D, Olivier V, Fabien P. Giant coronary aneurysms, from diagnosis to treatment: A literature review. Arch Cardiovasc Dis 2020; 113: 159-169.

3. Sara AS, Ozge OT, Özgür Ta, Omer G, Ismail DK. Coronary Artery Aneurysms: A Review of the Epidemiology, Pathophysiology, Diagnosis, and Treatment. Front Cardiovasc Med 2020; 4: 24.

4. Burns JC, Franco A. The immunomodulatory effects of intravenous immunoglobulin therapy in Kawasaki disease. Expert Rev Clin Immunol 2015; 11: 819-825.

5. Janeway CJ, Medzhitov R. Innate immune recognition. Annu Rev Immunol 2002; 20: 197-216.

6. Matsubara T, Ichiyama T, Furukawa S. Immunological profile of peripheral blood lymphocytes and monocytes/macrophages in Kawasaki disease. Clin Exp Immunol 2015; 141: 381-387.

7. Jia S, Li C, Wang G, Yang J, Zu Y. The T helper type 17/regulatory T cell imbalance in patients with acute Kawasaki disease. Clin Exp Immunol 2010; 162: 131-137.

8. Su R, Li ZH, Wang YY, et al. Imbalance between Th17 and regulatory T cells in patients with systemic lupus erythematosus combined EBV/CMV viraemia. Clin Exp Rheumatol 2020; 38: 864-873.

9. Jan L, Fausto P, Hendrik SK, Alla S. Altered T cell plasticity favours Th17 cells in early arthritis. Rheumatology (Oxford) 2020;59: 2754-2763.

10. Peng D, Xu BC, Wang Y, Guo H, Jiang YF. A high frequency of circulating th22 and th17 cells in patients with new onset graves' disease. PLoS One 2013; 8: e68446.

11. Anders D, Sidsel S, Tue KR, et al. Increased levels of circulating Th17 cells in quiescent versus active Crohn's disease. J Crohns Colitis 2020; 7: 248-255.

12. Manoochehr R, Behzad H, Mehdi K. Downregulation of Th17 cells and the related cytokines with treatment in Kawasaki disease. Immunol Lett 2014; 162: 269-275.

13. Ma L, Zhang LW, Zhuang Y, Ding YB, Chen JP. The Imbalance between Foxp3+Tregs and Th1/Th17/Th22 Cells in Patients with Newly Diagnosed Autoimmune Hepatitis. J Immunol Re. 2018; 1: e3753081.

14. Yang XY, Wang HY, Zhao XY, Wang LJ, Lv QH, Wang QQ. Th22, but not Th17 might be a good index to predict the tissue involvement of systemic lupus erythematosus. J Clin Immunol 2013; 33: 767-774.

15. Zhang L, Li JM, Liu XG, et al. Elevated Th22 cells correlated with Th17 cells in patients with rheumatoid arthritis. J Clin Immunol 2011;31: 606-614.

16. Li L, Han SX, Wang H, Liu XM. Down-regulation of the Th1, Th17, and Th22 pathways due to antiTNF- $\alpha$ treatment in psoriasis. Int Immunopharmacol 2015; 29: 278-284.

17. Luo Y, Yang J, Zhang C, et al. Up-regulation of miR-27a promotes monocyte-mediated inflammatory responses in Kawasaki disease by inhibiting function of B10 cells. J Leukoc Biol 2020; 107:133-144.

18. Keiichi K, Minako H, Takeshi M, et al. Plasma Exchange Downregulates Activated Monocytes and Restores Regulatory T Cells in Kawasaki Disease. Ther Apher Dial 2019; 23: 92-98.

19. Laurent D, Audrey D, Léamarie MD, Anne F, Nagib D. Echocardiographic Parameters During and Beyond Onset of Kawasaki Disease Correlate with Onset Serum N-Terminal pro-Brain Natriuretic Peptide (NT-proBNP). Pediatr Cardiol 2020; 41: 947-954.

20. Zheng Q, Chris D, Hu J, Hannelien V, Sofie S, Jo VD, Ghislain O. Interleukin-17 regulates chemokine and gelatinase B expression in fibroblasts to recruit both neutrophils and monocytes. Immunobiology 2009;

214: $835-842$. 
21. Éric T, Caroline L, Béatrice G, Damien G, Philippe S. Increased IL-22- and IL-17A-Producing MucosalAssociated Invariant T Cells in the Peripheral Blood of Patients With Ankylosing Spondylitis. Front Immunol 2018; 9: 1610 .

22. Kenneth MM. Effector T cell plasticity: flexibility in the face of changing circumstances. Nat Immunol 2010; 11: $674-680$.

23. Guo C, Tan CC, Xia XH, et al. Tumour necrosis factor- $\alpha$ and myoglobin associated with the recovery time of coronary artery lesions in Kawasaki disease patients. J Paediatr Child Health 2020; 56: 1382-1387.

24. Zhang RL, Lo HH, Lei C, Ip N, Chen J, Law BYK. Current pharmacological intervention and development of targeting IVIG resistance in Kawasaki disease. Curr Opin Pharmacol 2020; 54:72-81.

Figure Legends

Fig. 1 FACS analysis of the numbers of different subsets of circulating $\mathrm{CD3}^{+} \mathrm{CD}^{+} \mathrm{T}$ cells in KD patients.

PBMCs were isolated from individual subjects and PBMCs $5 * 10^{5} /$ tube were stained in duplicate with PECy5-anti-CD3 and PerCP-anti-CD4 or isotype controls, fixed and permeabilized, followed by intracellular staining with FITC-anti-IL-17, PE-Cy7-anti-IFN- $\gamma$, and PE-anti-IL-22. The frequency of $\mathrm{CD} 3{ }^{+} \mathrm{CD} 4^{+} \mathrm{IL}-$ $22^{+} \mathrm{Th} 22, \mathrm{CD}^{+}{ }^{+} \mathrm{CD} 4^{+} \mathrm{IL}-17^{+} \mathrm{Th} 17$ and $\mathrm{CD} 3{ }^{+} \mathrm{CD} 4^{+} \mathrm{IFN}-\gamma^{+} \mathrm{Th} 1$ cells were determined by flow cytometry analysis. The cells were gated on living lymphocytes and then gated on $\mathrm{CD} 3^{+} \mathrm{CD} 4^{+}$cells, and at least about 30,000 events were analyzed for each sample. The numbers of each type of CD $3^{+} \mathrm{CD} 4^{+} \mathrm{IL}-22^{+} \mathrm{Th} 22$, $\mathrm{CD}^{+}{ }^{+} \mathrm{CD} 4{ }^{+} \mathrm{IL}-17^{+} \mathrm{Th} 17$ and $\mathrm{CD} 3^{+} \mathrm{CD} 4{ }^{+} \mathrm{IFN}-\gamma^{+}$Th1 cells were calculated, according to the total numbers of PBMCs, the frequency of different types of $\mathrm{CD} 3^{+} \mathrm{CD} 4^{+} \mathrm{T}$ cells. (A). Flow cytometry analysis; (B). The numbers of $\mathrm{CD} 3{ }^{+} \mathrm{CD} 4^{+} \mathrm{IL}-22^{+} \mathrm{Th} 22$ cells; (C). $\mathrm{CD} 3{ }^{+} \mathrm{CD} 4^{+} \mathrm{IL}-17^{+}$Th17 cells; (D). CD $3^{+} \mathrm{CD} 4^{+} \mathrm{IFN}-\gamma^{+}$Th1 cells. Data shown are representative FACS charts or the mean numbers of each type of cells per $\mathrm{ml}$ of peripheral blood in individual subjects from two separate experiments. The horizontal lines indicate the median values for each group. Data shown are representative charts of different subsets of $\mathrm{CD} 3^{+} \mathrm{CD} 4{ }^{+} \mathrm{T}$ cells from individual groups of subjects $(n=20$ for the $\mathrm{HC}, \mathrm{n}=17$ for the patients with CAL, and $n=26$ for the patients with NCAL).
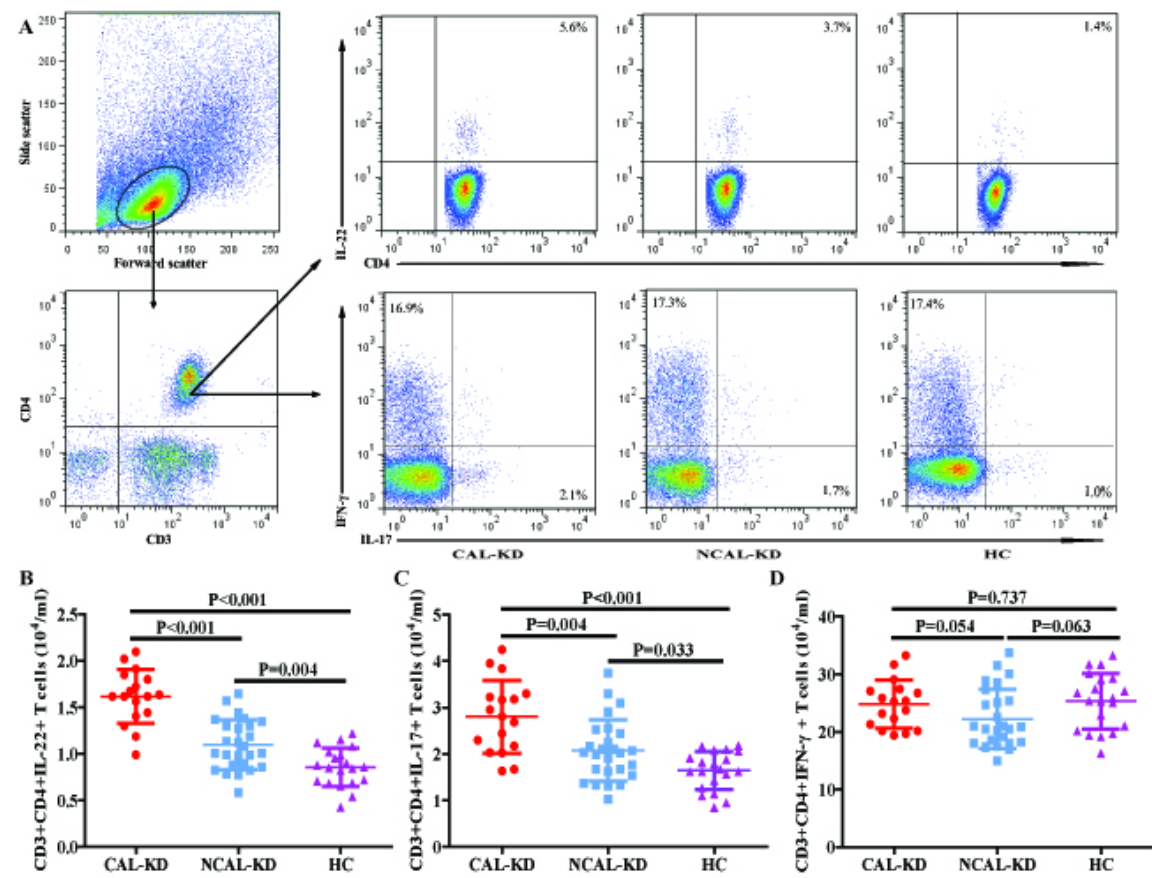
Fig. 2 ELISA analysis of the concentrations of serum cytokines in KD patients.

The concentrations of serum IL-17, IL-22, IFN- $\gamma$, TNF- $\alpha$ and IL- 6 in individual subjects were measured by ELISA. (A). Serum levels of IL-22; (B). Serum levels of IL-17; (C). Serum levels of IFN- $\gamma$ (D). Serum levels of TNF- $\alpha \cdot($ E). Serum levels of IL-6. The horizontal lines indicate the median values for each group. Data shown are serum cytokines from individual groups of subjects $(n=20$ for the $\mathrm{HC}, \mathrm{n}=17$ for the patients with CAL, and $n=26$ for the patients with NCAL).
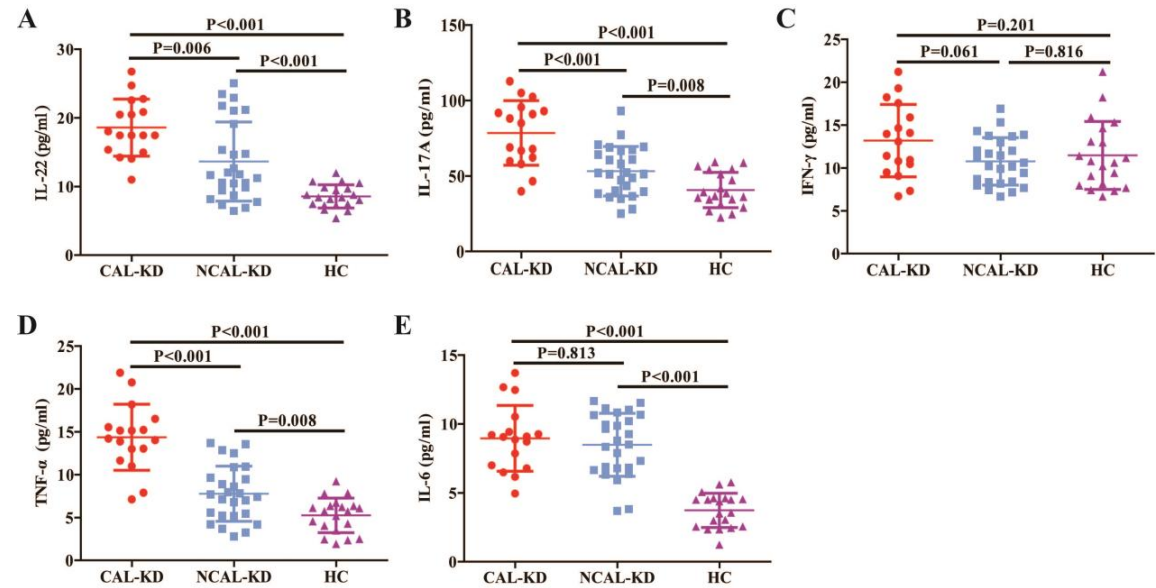

Fig. 3 Correlation among the numbers of different subsets of circulating $\mathrm{CD}^{+} \mathrm{CD} 4^{+} \mathrm{T}$ cells and the concentrations of serum cytokines in KD patients.

Correlation between the numbers of $\mathrm{CD} 3^{+} \mathrm{CD} 4^{+} \mathrm{IL}-22^{+} \mathrm{Th} 22$ cells and the numbers of $\mathrm{CD} 3^{+} \mathrm{CD} 4^{+} \mathrm{IL}-$ $17^{+}$Th17 cells (A), serum IL-22 (B) and serum TNF- $\alpha$ (C) in patients with CAL; Correlation between the numbers of $\mathrm{CD} 3{ }^{+} \mathrm{CD} 4^{+} \mathrm{IL}-17^{+} \mathrm{Th} 17$ cells and serum IL-17A (D) in patients with CAL; Correlation between the numbers of $\mathrm{CD} 3^{+} \mathrm{CD} 4{ }^{+} \mathrm{IL}-22^{+} \mathrm{Th} 22$ cells and the numbers of CD3 ${ }^{+} \mathrm{CD} 4{ }^{+} \mathrm{IL}-17^{+} \mathrm{Th} 17$ cells (A), serum IL-22 (B) and serum TNF- $\alpha$ (C) in patients with NCAL; Correlation between the numbers of CD $3^{+} \mathrm{CD} 4{ }^{+} \mathrm{IL}-17^{+}$Th17 cells and serum IL-17A (D) in patients with NCAL.
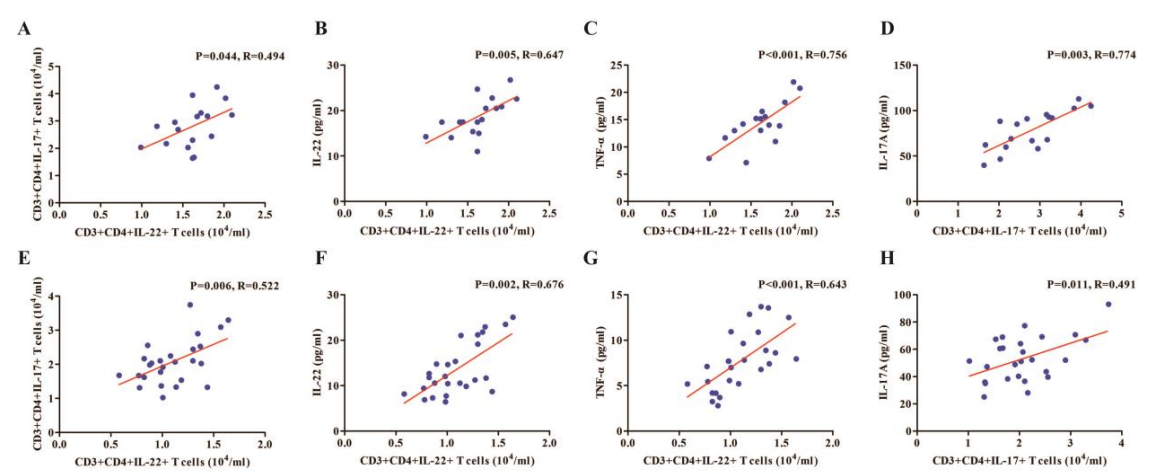

Fig. 4 Correlation between serum levels of $\mathrm{CD}^{+} \mathrm{CD} 4^{+} \mathrm{T}$ cell-related cytokines and the values of clinical parameters in KD patients.

Correlation between serum levels of IL-22 and ESR/CRP/NT-proBNP in KD patients with CAL; (B) Correlation between serum levels of IL-17A and ESR/CRP/ NT-proBNP in KD patients with CAL; (C) Correlation between serum levels of IL-22 and ESR/CRP/NT-proBNP in KD patients with NCAL; (D) Correlation between serum levels of IL-17A and ESR/CRP/ NT-proBNP in KD patients with NCAL. 
A
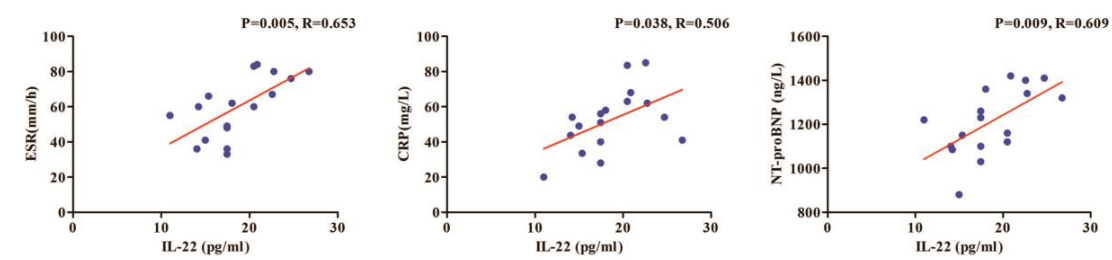

B
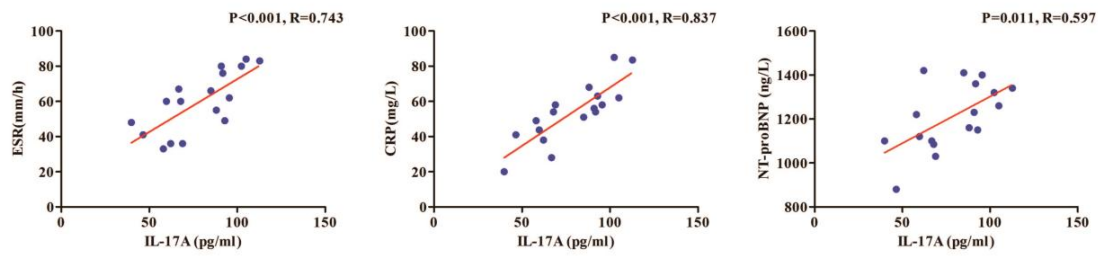

C
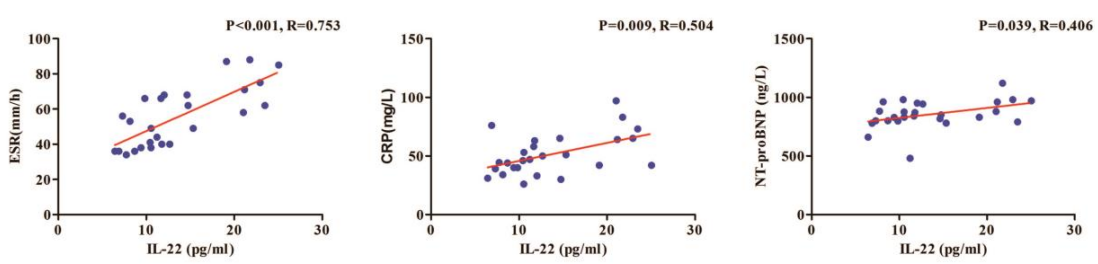

D
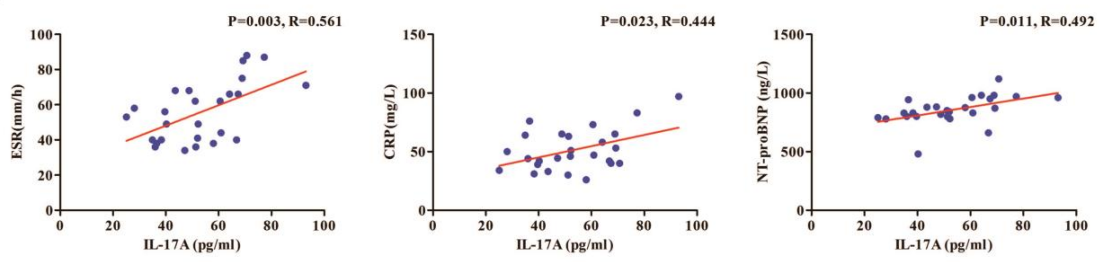

Fig. 5 The effects of IVIG therapy on the numbers of Th22/Th17 cells and related cytokines in $\mathrm{KD}$ patients.

The numbers of $\mathrm{CD} 3{ }^{+} \mathrm{CD} 4{ }^{+} \mathrm{IL}-22^{+} \mathrm{Th} 22, \mathrm{CD} 3^{+} \mathrm{CD} 4^{+} \mathrm{IL}-17^{+} \mathrm{Th} 17$ and the levels of serum IL-22, IL-17A and TNF- $\alpha$ in CAL (A) and NCAL (B) patients pre- and posttreatment. 

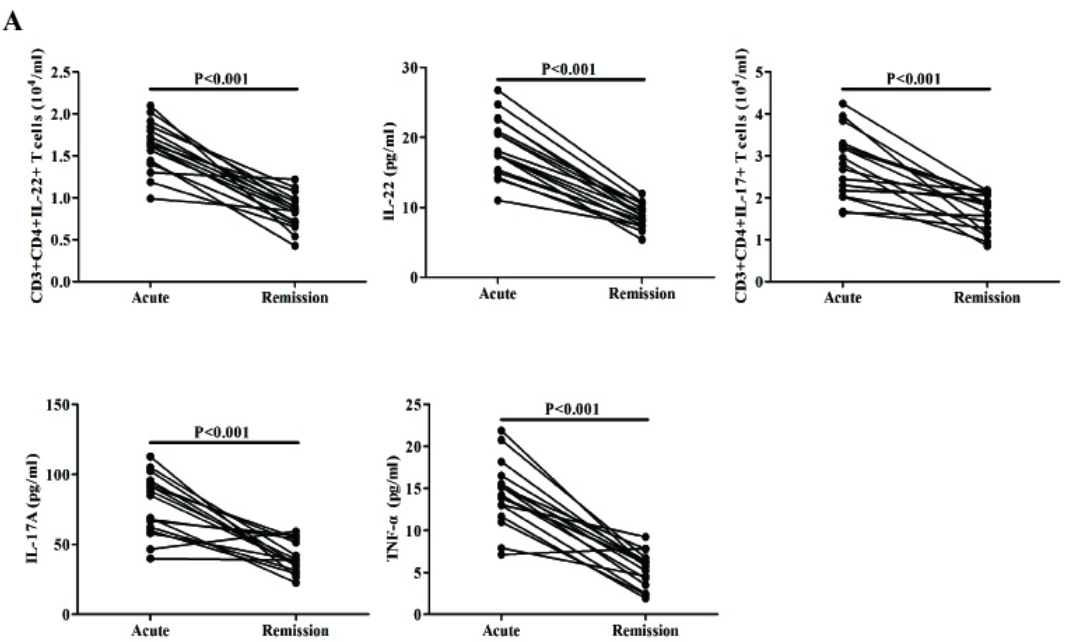

B
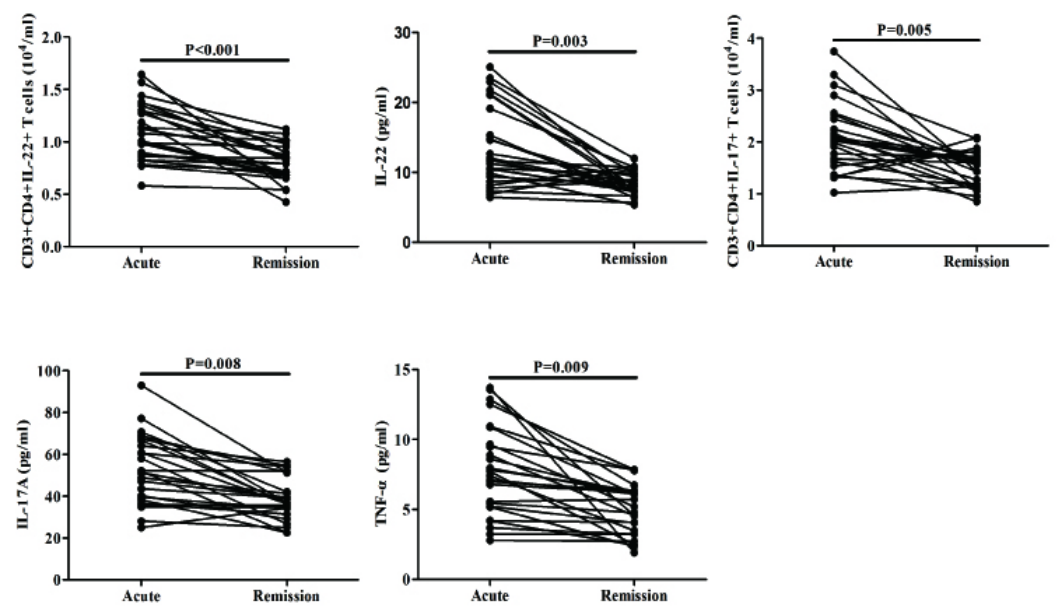

Table 1. The demographic and clinical characteristics of subjects.

\begin{tabular}{llll}
\hline Parameters & CAL-KD & NCAL-KD & HC \\
NO. & 17 & 26 & 20 \\
Age $($ years $)$ & $3.5 \pm 1.8$ & $3.2 \pm 2.4$ & $2.9 \pm 1.8$ \\
Gender:female/male & $9 / 8$ & $14 / 12$ & $11 / 9$ \\
WBC $\left(\times 10^{9} / \mathrm{L}\right)$ & $14.45 \pm 2.37^{*}$ & $14.46 \pm 2.98^{*}$ & $5.08 \pm 3.2$ \\
Neutrophils $\left(\times 10^{9} / \mathrm{L}\right)$ & $10.56 \pm 1.76^{*}$ & $10.22 \pm 2.86^{*}$ & $2.62 \pm 1.34$ \\
Lymphocytes $\left(\times 10^{9} / \mathrm{L}\right)$ & $3.25 \pm 1.39^{*}$ & $3.11 \pm 1.54^{*}$ & $2.12 \pm 0.74$ \\
ESR $(\mathrm{mm} / \mathrm{h})$ & $59.77 \pm 17.28^{*}$ & $55.77 \pm 16.91^{*}$ & $6.53 \pm 2.62$ \\
CRP $(\mathrm{mg} / \mathrm{L})$ & $52.34 \pm 17.50^{*}$ & $51.4 \pm 17.62^{*}$ & $2.12 \pm 0.83$ \\
NT-proBNP $(\mathrm{ng} / \mathrm{L})$ & $1210.9 \pm 152.07^{* \#}$ & $855.96 \pm 120.49$ & $\mathrm{ND}$ \\
IgG $(\mathrm{g} / \mathrm{L})$ & $9.89 \pm 2.33$ & $9.06 \pm 5.6$ & $\mathrm{ND}$ \\
IgM $(\mathrm{g} / \mathrm{L})$ & $1.29 \pm 0.47$ & $1.20 \pm 0.49$ & $\mathrm{ND}$ \\
IgA $(\mathrm{g} / \mathrm{L})$ & $2.04 \pm 0.69$ & $1.95 \pm 0.83$ & $\mathrm{ND}$ \\
C3 $(\mathrm{g} / \mathrm{L})$ & $1.18 \pm 0.26$ & $1.12 \pm 0.19$ & $\mathrm{ND}$ \\
$\mathrm{C} 4(\mathrm{~g} / \mathrm{L})$ & $0.26 \pm 0.06$ & $0.25 \pm 0.07$ & $\mathrm{ND}$ \\
\hline
\end{tabular}


Data shown are real case number or mean \pm SD.

Normal values: White blood cell counts (WBC):4-10 $\times 10^{9} / \mathrm{L}$; Erythrocyte sedimentation rate (ESR): 0$20 \mathrm{~mm} / \mathrm{h}$; C-reactive protein (CRP):0-5 mg/L; N-terminal pronatriuretic peptide (NT-proBNP): $<300 \mathrm{pg} / \mathrm{ml}$; IgG: 7-16 g/L; IgM: 0.7-4.6 g/L; IgA:0.4-2.3 g/L; Complement component 3(C3):0.80-1.40g/L; Complement $4(\mathrm{C} 4): 0.20-0.70 \mathrm{~g} / \mathrm{L} ; \mathrm{ND}$ : not determined. HC, healthy control; CAL-KD, Coronary Artery Lesions Kawasaki disease. ${ }^{*} \mathrm{P}<0.05$ vs $\mathrm{HC} ;{ }^{\#} \mathrm{P}<0.05$ vs. NCAL-KD . 